\title{
Reporter Fluorescent Molecules in Biological Systems: The Current Overview
}

\author{
Adam Lesner* \\ Faculty of Chemistry, Gdansk University, Sobieskiego 18, 80-952 Gdansk, Poland
}

Labeling molecules without losing its activity has a long track in science. The first labeling method for detection of the biomolecules was the use of radioisotope entities like ${ }^{32} \mathrm{P}$, which have been successfully employed to study protein-protein, protein-DNA, protein-RNA and protein-ligand interactions. In the past years however, radioisotope utilization as label has declined due to safety and health concerns [1]. Various kind of fluorophore moieties as suitable alternative has been developed and widely accepted. Dyes such as rhodamine, fluoroscein, phycobiliproteins, nitrobenzoxadiazole, acridines, BODIPY and cyanine compounds or their derivates are most commonly used as a reporter molecule. The choice of fluorophore molecule to be used for detection depends on the sample type, substrate, the number of analyzed molecules in the experiments and light emission spectra characteristics [2]. Cyanine dyes, Cy3 and Cy5, are among are a good example of dyes used due to their brightness and ability to easily label proteins with $\varepsilon$-amino group of lysine residues [3]. Detection using the fluorescence labeling can be performed in two ways: by direct labeling (one antibody assay) or indirect labeling [4]. In the direct labeling method, the selected protein is labeled directly with a fluorophore (Cy3 or Cy5), which interacts with, immobilized on the surface of the chip, antibodies. This method allows simultaneous incubation of a reference sample with tested sample, both having different dyes attached [5].

Bodipy that is acronym of 4,4-difluoro-4-bora-3a,4a-diaza-sindacene are the highly fluorescent molecule that is alternative for $\mathrm{Cy}$ dyes. Pei and coworkers [6] constructed chip that performance was evaluated by performing assays for $\mathrm{G}$ protein GTPase activity on chip using BODIPY-GTP as enzyme substrate.

\section{Nanomolecules}

Quantum dots (Qdot) and gold nanoparticles [7,8] are another group of fluorescence emitting molecules. The Qdot is a nano-metal fluorophore with bright and linear signal of emitted light. One advantage of using Qdot is that it has no photo-bleaching effect that often occurs while using organic fluorophores which combined with narrow emission spectra and greater quantum yield [9] makes the quantum dots an excellent alternative for conventional fluorophores. Indeed Qdots find a diverse range of applications in biological sciences such as diagnostic imaging [10], detection of cancer biomarkers $[11,12]$, and probing of human serum [13]. However the low stability and short lifetime of Qdots due to their susceptibility to oxidation are the main shortcoming of these methods.

\section{Rare Metal Chelates}

Rare metal (lanthanide) complexes are found to be highly fluorescent and long lasting fluorophore species [14]. In late 80's of the last century, intrinsically fluorescent lanthanide chelates were developed, which made them viable donors in FRET applications. Lanthanide chelates have exclusive properties that make them excellent donors compared to organic dyes. Lanthanide chelates have long lifetimes that enable time-resolved measurement of acceptor emission, which significantly decreases the effect of autofluorescence and possible direct acceptor excitation.

\section{Bioluminescence}

Light emission (luminescence) is another method to visualize the target/captured protein. Biotin market proteins or protein with attached Strep tag that is peptide that reveal high affinity for streptavidin, are applied on microarray system. Light intensity boost is observed as positive output after incubation with streptavidin conjugated with fluorophore [15] or horse radish peroxidase in presence of appropriate substrate [16]. In the last paper using this biotin label-based antibody array technology, the expression levels of 507 human, 308 mouse and 90 rat target proteins can be simultaneously detected, including chemokines, growth factors, cytokines angiogenic factors, proteases, soluble receptors, soluble adhesion molecules, and other proteins in a variety of samples. Most proteins can be detected at $\mathrm{pg} / \mathrm{ml}$ and $\mathrm{ng} /$ $\mathrm{ml}$ levels.

Another strategy important to evaluate bimolecular interactions is a FRET based compounds (Fluorescence Resonance Energy Transfer) $[17,18]$. Since the efficiency of FRET depends on distance between target molecules (containing donor and acceptor of fluorescence) this effect is easily adapted for two labeled molecules. The system with two labeled interacting molecules display upon excitation low fluorescence intensity due to high FRET occurrence. Single molecules display high fluorescence intensity. Another important filed utilisation of fluorescent dyes is to follow the activity of proteolytical enzymes by FRET displaying molecules. This issue has been generally recognize as a method of choice in construction of fluorescent substrates $[19,20]$ or molecular probes [21].

\section{Closing remarks}

The analysis of biomolecule is a demanding issue due to complexity of the origin sample (blood, serum, tissue). Therefore there is an ongoing need to improve the final read out in sense of the sensitivity and stability of the fluorophores. Novel fluorescent materials like quantum dots or new organic dyes have proven to be a progress in this area. Luminescence-based detection or its combination with fluorescent one is a good example of upcoming systems.

\section{References}

1. Martin K, Steinberg TH, Cooley LA, Gee KR, Beechem JM, et al. (2003) Quantitative analysis of protein phosphorylation status and protein kinase activity on microarrays using a novel fluorescent phosphorylation sensor dye. Proteomics 3:1244-1255

*Corresponding author: Adam Lesner, Faculty of Chemistry, Gdansk University, Sobieskiego 18,80-952 Gdansk, Poland, E-mail: adas@chem.univ.gda.pl

Received July 17, 2012; Accepted July 18, 2012; Published July 20, 2012

Citation: Lesner A (2012) Reporter Fluorescent Molecules in Biological Systems: The Current Overview. Biochem Anal Biochem 1:e111. doi:10.4172/2161. 1009.1000e111

Copyright: (c) 2012 Lesner A. This is an open-access article distributed under the terms of the Creative Commons Attribution License, which permits unrestricted use, distribution, and reproduction in any medium, provided the original author and source are credited. 
Citation: Lesner A (2012) Reporter Fluorescent Molecules in Biological Systems: The Current Overview. Biochem Anal Biochem 1:e111. doi:10.4172/2161-1009.1000e111

Page 2 of 2

2. Chandra H, Reddy PJ, Srivastava S (2011) Protein microarrays and novel detection platforms. Expert Rev Proteomics 8: 61-79.

3. Zou W, Al-Khaldi SF, Branham WS, Han T, Fuscoe JC, et al. (2011) Microarray analysis of virulence gene profiles in Salmonella serovars from food/food animal environment. J Infect Dev Ctries 5: 94-105.

4. LaBaer J, Ramachandran N (2005) Protein microarrays as tools for functional proteomics. Curr Opin Chem Biol 9: 14-19.

5. Miller JC, Zhou H, Kwekel J, Cavallo R, Burke J, et al. (2003) Antibody microarray profiling of human prostate cancer sera: antibody screening and identification of potential biomarkers. Proteomics 3: 56-63.

6. Pei J, Dishinger JF, Roman DL, Rungwanitcha C, Neubig RR, et al (2008) Microfabricated channel array electrophoresis for characterization and screening of enzymes using RGS-G protein interactions as a model system. Anal Chem 80: 5225-5231.

7. Pinaud F, Michalet X, Bentolila LA, Tsay JM, Doose S, et al. (2006) Advances in fluorescence imaging with quantum dot bio-probes. Biomaterials 27: 16791687.

8. Rao J, Dragulescu-Andrasi A, Yao H (2007) Fluorescence imaging in vivo: recent advances. Curr Opin Biotechnol 18: 17-25.

9. Ray S, Chandra H, Srivastava S (2010) Nanotechniques in proteomics: current status, promises and challenges. Biosens Bioelectron 25: 2389-2401.

10. Sun YP, Zhou B, Lin Y, Wang W, Fernando KA (2006) Quantum-sized carbon dots for bright and colorful photoluminescence. J Am Chem Soc 128: 77567757.

11. Jokerst JV, Raamanathan A, Christodoulides N, Floriano PN, Pollard AA, et al. (2009) Nano-bio-chips for high performance multiplexed protein detection: determinations of cancer biomarkers in serum and saliva using quantum dot bioconjugate labels. Biosens Bioelectron 24: 3622-3629.

12. Hu M, Yan J, He Y, Lu H, Weng L, et al. (2010) Ultrasensitive, multiplexed detection of cancer biomarkers directly in serum by using a quantum dot-based microfluidic protein chip. ACS Nano 4: 488-494.

13. Zajac A, Song D, Qian W, Zhukov T (2007) Protein microarrays and quantum dot probes for early cancer detection. Colloids Surf B Biointerfaces 58: 309 314.

14. Jiang H, Wang G, Zhang W, Liu X, Ye Z, et al. (2010) Preparation and timeresolved luminescence bioassay application of multicolor luminescent lanthanide nanoparticles. J Fluoresc 20: 321-328.

15. Lee Y, Park S, Park J, Koh WG (2010) Micropatterned assembly of silica nanoparticles for a protein microarray with enhanced detection sensitivity. Biomed Microdevices 12: 457-464.

16. Huang R, Jiang W, Yang J, Mao YQ, Zhang Y, et al. (2010) A biotin labelbased antibody array for high-content profiling of protein expression. Cancer Genomics Proteomics 7: 129-141.

17. Förster T (1948) Zwischenmolekulare Energiewanderung und Fluoreszenz, Ann Phys 437: 55-75.

18. Díaz-Mochón JJ, Bialy L, Bradley M (2006) Dual colour, microarray-based analysis of 10,000 protease substrates. Chem Commun (Camb) 38: 3984 3986.

19. Lesner A, Wysocka M, Guzow K, Wiczk W, Legowska A, et al. (2008) Development of sensitive cathepsin $\mathrm{G}$ fluorogenic substrate using combinatorial chemistry methods. Anal Biochem 375: 306-312.

20. Wysocka M, Lesner A, Majkowska G, Legowska A, Guzow K, et al. (2010) The new fluorogenic substrates of neutrophil proteinase 3 optimized in prime site region. Anal Biochem 399: 196-201.

21. Pan Z, Jeffery DA, Chehade K, Beltman J, Clark JM, et al. (2006) Development of activity-based probes for trypsin-family serine proteases. Bioorg Med Chem Lett 16: 2882-2885. 